\title{
Uso de técnicas de Geoprocessamento para análise dos processos erosivos na microbacia do rio da Ribeira, Santa Rita (PB): uma análise a partir da ocupação do relevo
}

\author{
Use of GIS techniques for analysis of erosion in the watershed of the river Ribeira, Santa \\ Rita (PB)
}

\author{
SANTOS ${ }^{1}$, C. L.; SILVA $^{2}$, J. P.
}

caiolimageo@gmail.com;

\begin{abstract}
Resumo
A forma como o homem tem se apropriado dos recursos naturais vem originando diversos problemas de ordem ambiental, o que reflete diretamente na diminuição dos recursos naturais e da qualidade de vida das pessoas. Nesse contexto, a erosão constitui parte dos processos degenerativos da paisagem natural. Localizada no município de Santa Rita, estado da Paraíba, A microbacia do rio da Ribeira constitui um exemplo atual de uma área onde esses processos estão diretamente associados à dinâmica do uso das terras. O presente trabalho teve como objetivo analisar o nível de suscetibilidade desta microbacia à ocorrência de processos erosivos a partir da análise de informações referentes ao uso das terras e à geomorfologia, visando verificar o grau de influência da apropriação do espaço geográfico na gênese de feições erosivas/deposicionais em diferentes unidades do relevo. Os procedimentos técnico-operacionais adotados para este fim consistiram no mapeamento geomorfológico da área, utilizando como base metodológica as instruções contidas em Ross (1992). Num segundo momento, os mapas de uso da terra, declividade e das unidades geomorfológicas foram submetidos a um processo de álgebra, utilizando um Sistema de Informações Geográficas, tendo como produto um mapa de suscetibilidade erosiva da microbacia estudada.
\end{abstract}

Palavras-chave: Erosão, geoprocessamento, microbacia do rio da Ribeira, Santa Rita (PB).

\begin{abstract}
The way the man has appropriated natural resources, is causing many problems to the environment, which directly reflects the depletion of natural resources and people's quality of life. In this context, the erosion is part of the degenerative processes of the natural landscape. The watershed of the river Ribeira, in the municipality of Santa Rita, state of Paraíba, is a current example of an area where these processes are directly associated with the dynamics of land use. This study aimed to analyze the susceptibility level of this watershed to the occurrence of erosion from the analysis of information relating to land use and geomorphology, in order to verify the degree of influence of appropriation of space geographic the genesis of erosional / depositional features in different relief units. The technical and operational procedures adopted for this purpose consisted of geomorphological mapping of the area, using as methodological basis, the instructions contained in Ross (1992). In a second moment, maps of land use, declivity and geomorphological units were submitted to an algebra process, using a Geographic Information System, having as a product, a map of erosive susceptibility of the studied microbasin.
\end{abstract}

Keywords: Erosion, geoprocessing, Watershed River Ribeira, Santa Rita (PB).

\section{INTRODUÇÃO}

O relevo terrestre é resultado da relação estabelecida entre os processos tectônicos e as ações bioclimáticas, onde o primeiro atua, sobretudo, na estrutura e o segundo, é responsável pelo modelado. É através dessa associação complexa de processos que são esculturadas as diversas paisagens naturais. 
A ciência geomorfológica procura compreender as formas de relevo, em diferentes escalas espaciais e temporais, explicando não só a sua gênese, mas também como evoluem no tempo e no espaço. Essa evolução se dá de modo natural, a partir da interação dos agentes do intemperismo associados às características litológicas de cada lugar. Porém, não se podem desprezar as ações antrópicas, uma vez que, apropriando-se do solo para desenvolver suas atividades, o homem se torna um importante agente de transformação do relevo (ARAUJO et al., 2007).

As atividades agrícolas representam uma importante ação humana que tem influenciado diretamente as alterações nos sistemas ambientais, principalmente sobre o relevo. Nesse contexto, é comum a associação de processos erosivos a atividades agrícolas, com maior ênfase as atividades ligadas à monocultura. Montgomery (2007a) destaca que o processo de aração do solo aumenta em até duas vezes as taxas de erosão em relação as condições naturais de erosão dos solos, tornando-se uma forma de manejo insustentável. Guerra e Marçal (2012) afirmam que o uso intensivo do solo sem a adoção de práticas conservacionistas tem gerado sérios problemas de erosão.

No intuito de propor soluções práticas para minimizar os impactos causados nos solos decorrentes do desenvolvimento de atividades agrícolas, diversos trabalhos veem sendo desenvolvidos no âmbito das ciências ambientais utilizando-se do aporte tecnológico proporcionado pelo desenvolvimento das geotecnologias. O uso do geoprocessamento tonou-se uma prática recorrentes e indispensável nos estudos ambientais mediante sua capacidade de extrair, armazenar e manipular informações geoespaciais.

Fujihara (2002) destaca que a análise de cenários de risco de erosão e do potencial de uso da terra com auxílio de sistema de informação geográfica (SIG) representou uma importante ferramenta para o diagnóstico e para o planejamento ambiental, por permitir maior agilidade no desenvolvimento do processo e a possibilidade de simular e analisar diversos cenários. Do mesmo modo, Beskow et al (2009) confirmam tal ideia, afirmando que o mapeamento e avaliação dos riscos de erosão com o auxílio de SIG representa um procedimento eficaz para o planejamento e gestão dos recursos naturais, bem como para a prevenção de impactos e manejo do solo.

Tendo em vista a observação de alguns aspectos, como o predomínio da atividade agrícola canavieira desprovida de técnicas adequadas de manejo em quase toda extensão da microbacia do rio da Ribeira; ocorrência de diversas feições erosivas, tanto em áreas de uso agrícola, como nos pequenos núcleos urbanos presentes na área, e a; inexistência de trabalhos pretéritos que abordam a temática para a referida área de estudo, representaram a motivação para a execução dessa pesquisa.

Desse modo, o presente trabalho teve como objetivo, analisar o nível de suscetibilidade desta microbacia à ocorrência de processos erosivos a partir da análise de informações referentes ao uso das terras e as características do relevo, usando como suporte técnicas de geoprocessamento. 
Assim, pretende-se verificar o grau de influência da apropriação do espaço geográfico na gênese de feições erosivas.

\subsection{LOCALIZAÇÃO E CARACTERIZAÇÃO DA ÁREA DE ESTUDO}

A área de estudo compreende uma porção da zona rural do município de Santa Rita (PB), correspondente à microbacia do rio Ribeira, localizado na margem esquerda do estuário do rio Paraíba do Norte. Entre outras bacias que compõem o baixo curso do rio Paraíba (Paroeira, Tibiri, Guia, Mandacarú, Sanhauá e Tambiá), a microbacia do rio da Ribeira se localiza a Oeste das Ilhas do Stuart e de Tibiri. Apresenta área total de $52 \mathrm{~km}^{2}$, e se enquadra em uma poligonal retangular delimitada pelas coordenadas geográficas 70'03”'S a 7०5'5”S de latitude e $34^{\circ} 59^{\prime} 49^{\prime \prime} \mathrm{W}$ a $34^{\circ} 51^{\prime} 40^{\prime \prime} \mathrm{W}$ de longitude (Figura 1).

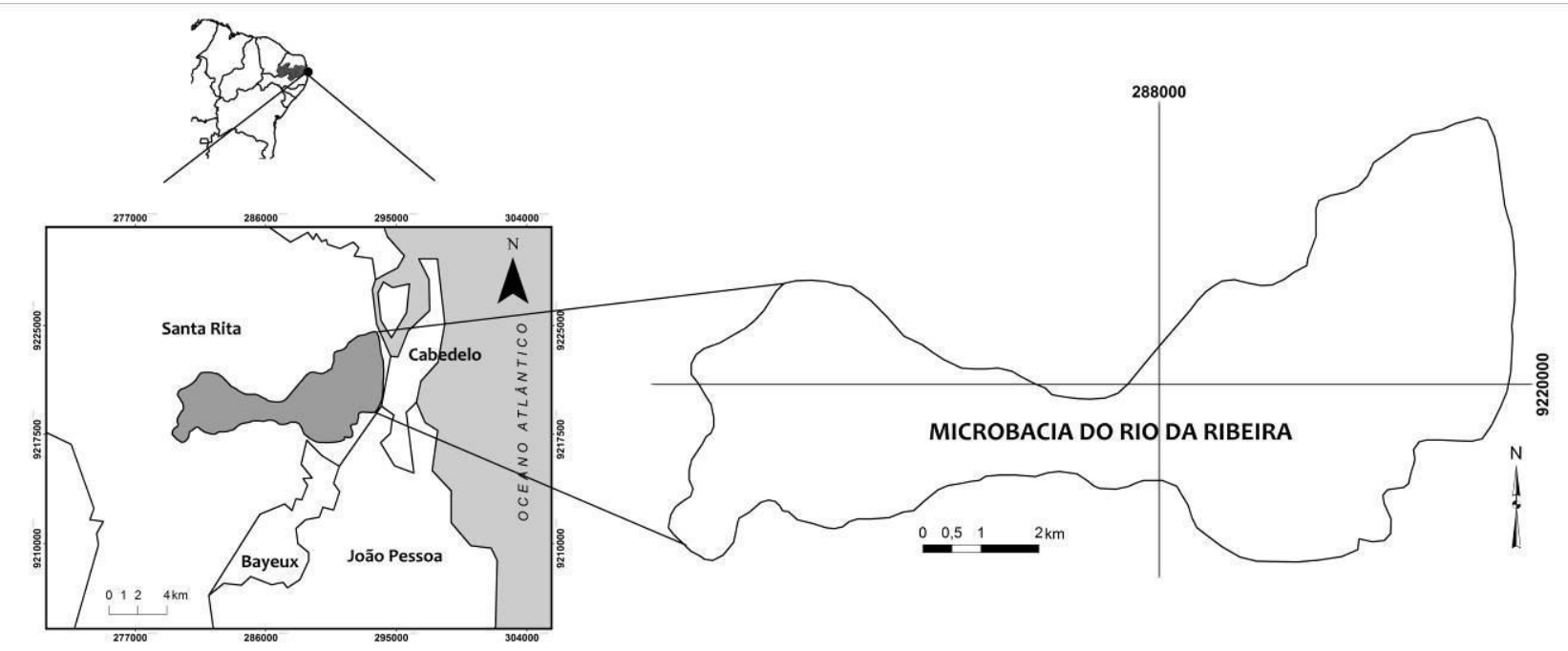

Figura 1: Localização da área de estudo.

Em relação ao contexto geológico, a referida bacia se encontra nos domínios da Bacia Sedimentar Paraíba, a qual é constituída por três unidades litoestratigráficas: a Formação Beberibe/Itamaracá, a Formação Gramame e a Formação Maria Farinha, que constitui o Grupo Paraíba, recoberto pelos sedimentos da Formação Barreiras, que constitui uma unidade de idade miocênica a pleistocênica inferior capeadora de outras bacias marginais brasileiras (Barbosa, 2007).

Quanto ao relevo, a área encontra-se inserida no contexto do Setor Oriental Úmido e Subúmido paraibano (Carvalho, 1982), abarcando as áreas sedimentares fluviomarinhas (mangues), áreas sedimentares continentais (baixo planalto costeiro com superfície preservada e dissecada, colinas residuais e planícies aluviais). 
O clima corresponde ao tipo Tropical Litorâneo, úmido e quente, apresentando maiores índices de pluviosidade nos meses de abril, junho e julho, com normal histórica de precipitação de 2.145,4mm (Pereira et al., 2012).

Em relação aos solos, predominam os tipos (UEP Recife, 2006): Podzólico VermelhoAmarelo (Argissolos), com maior ocorrência na área de estudo, seguido dos Solos Indiscriminados de Mangue (Organossolos) e Areias Quartzosas (Neossolos).

A vegetação é composta, em sua maioria, por remanescentes de Floresta Atlântica, onde se observa uma cobertura heterogênea, com indivíduos de 5 a 10 metros de altura, tendo como principais espécies: Rubiaceae, Fabaceae, Anacardiaceae e Boraginaceae. Além disso, também estão presentes espécies de Manguezal, com forte ocorrência nos estuários do rio Paraíba do Norte e Gramame, além de pequenas manchas de Cerrado no topo dos tabuleiros costeiros (Melo et al., 2001; Pereira; Alves, 2007).

Do ponto de vista agrícola e econômico, ocorre, nessa área, o predomínio de atividade monocultora canavieira, ocupando as áreas de várzea, vertentes e topos de tabuleiros. Até a década de 1970 essa cultura agrícola era restrita às áreas de condições naturais mais favoráveis, tais como as várzeas mais largas do litoral paraibano. Os tabuleiros costeiros constituíam um limite natural à expansão dessa atividade econômica em função, sobretudo, da baixa fertilidade dos seus solos. Entre 1970 e 1980, a área colhida de cana no estado cresceu 10,5\%, o que representou um acréscimo de 58.000 hectares de área plantada. A área colhida passou de 120 mil hectares para 178 mil hectares nesse período, fato permitido pelo incremento tecnológico adotado na produção agrícola, com a utilização de substâncias químicas como corretivos para o solo, fungicidas, pesticidas e vários outros tipos de agrotóxicos (Moreira e Targino, 1997).

\section{METODOLOGIA}

O presente trabalho adotou o método análogo dedutivo, os princípios geossistêmicos e a metodologia de mapeamento geomorfológico disponibilizada em Ross (1992). Inicialmente, foi feita uma pesquisa bibliográfica, compondo o referencial teórico e metodológico que orientou essa pesquisa. Em um segundo momento, foi realizado o levantamento cartográfico, baseando-se em cartas topográficas e imagens de satélites.

A delimitação da área de estudo foi realizada a partir da extração de informações altimétricas do terreno contidas em cartas topográficas de escala 1:25.000, correspondentes às folhas João Pessoa e Mata da Aldeia, utilizando um Sistema de Informações Geográficas.

A partir da vetorização das curvas de nível, tornou-se possível a confecção de um Modelo Digital de Elevação (MDE), a partir do qual foram obtidos dados de fluxo acumulado e direção de 
fluxo, possibilitando a distinção de drenagens com maior rigor de detalhe, ou seja, com limiar > 100. O nível da densidade de drenagens obtido a partir desse processo possibilitou a delimitação de diversas microbacias distribuídas ao longo da região do estuário do rio Paraíba do Norte, dentre elas, a microbacia do rio da Ribeira. Os limites da microbacia foram obtidos automaticamente confrontados com as curvas de nível existentes na carta topográfica de 1:25.000 para averiguação da confiabilidade do processo, onde foi constatada grande proximidade entre as informações.

Para a confecção do mapa de uso das terras, foram utilizadas imagens do satélite Rapideye, com resolução espacial de 5 metros, obtidas no Geocatálogo do IBAMA (Instituto Brasileiro de Meio Ambiente e dos Recursos Naturais Renováveis). Como base metodológica para distinção das classes de uso das terras, foi utilizada a proposta presente em Brasil (2006), que subdivide os diferentes usos em distintos níveis categóricos, perfazendo as áreas antrópicas não agrícolas, áreas antrópicas agrícolas, áreas de vegetação natural e água. As classes mapeadas foram validadas através das informações obtidas nos trabalhos de campo, quando também foram cadastradas as feições erosivas a partir da obtenção de suas coordenadas de localização.

O mapa das unidades geomorfológicas foi criado com base no Modelo Digital de Elevação e na imagem de satélite, tendo como base a proposta metodológica de Ross (1992).

Por fim, foi gerado um mapa de suscetibilidade erosiva a partir de um processo de álgebra, envolvendo os mapas de declividade, unidades geomorfológicas e uso das terras, utilizando um Sistema de Informações Geográficas, para os quais foram atribuídos os seguintes pesos (Tabela 1).

As informações referentes à declividade e ao uso das terras obtiveram pesos de 0,35 devido ao fato de terem grande influência nos processos erosivos da área, tendo em vista que os processos erosivos na localidade são bastante condicionados pelos tipos de culturas desenvolvidas, a exemplo da cana-de-açúcar, sobretudo em áreas de forte inclinação. Posteriormente, as unidades geomorfológicas obtiveram peso 0,30, tendo em vista o fato de terem sido definidas apenas duas grandes unidades, onde não foi possível obter um maior nível de detalhamento. Por esse motivo, atribuiu-se a este mapa um peso levemente inferior.

Tabela 1: Pesos utilizados para os mapas temáticos no processo de álgebra.

\begin{tabular}{lc}
\hline \multicolumn{1}{c}{ Classes } & Pesos \\
\hline Declividade & 0,35 \\
Uso das terras & 0,35 \\
Unidade Geomorfológica & 0,30 \\
\hline
\end{tabular}


Além disso, foram utilizados pesos para cada uma das classes dos mapas temáticos mencionados anteriormente (Tabela 2).

Tabela 2: Pesos atribuídos às classes dos mapas temáticos.

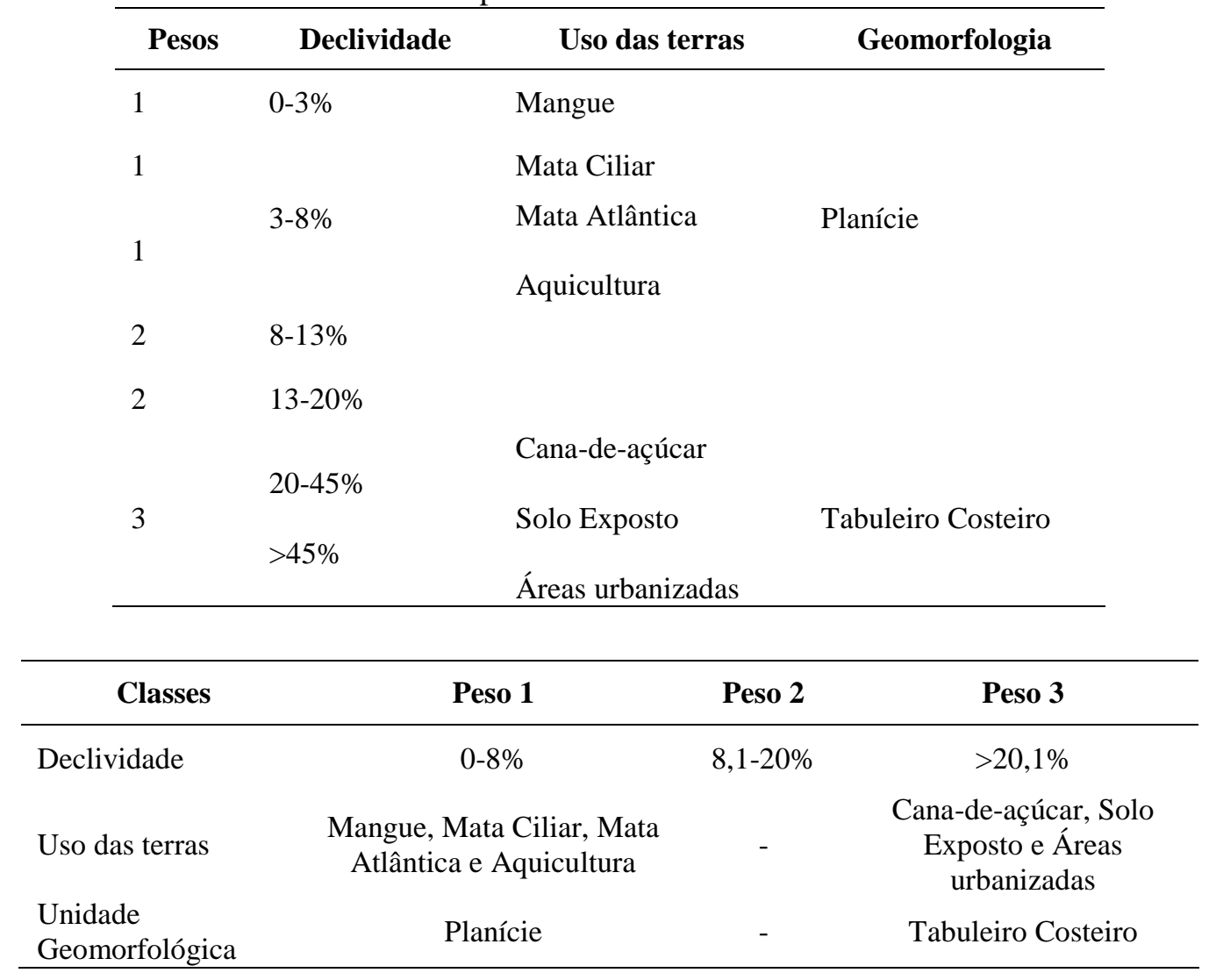

\section{RESULTADOS E DISCUSSÃO}

\subsection{USO DAS TERRAS}

As informações referentes ao uso das terras permitiram detectar os diferentes núcleos urbanos existentes no interior da microbacia analisada. Dessa forma, as áreas antrópicas nãoagrícolas são representadas por pequenos núcleos populacionais (Aterro, Livramento e Ribeira), bem como pelas áreas onde afloram o calcário da Formação Gramame, pois representam antigos locais de exploração dessa rocha. Esse nível de ocupação representa apenas $2 \%$ da área total da microbacia (Figura 2).

As áreas antrópicas agrícolas representam a maior parte das atividades econômicas desenvolvidas na microbacia. Esse nível de ocupação corresponde à principal forma de uso, perfazendo $46 \%$ da superfície, estando ocupada em quase sua totalidade pela cana-de-açúcar. Culturas de subsistência também foram observadas, porém, em função de ocuparem áreas 
diminutas, foram desconsideradas. Outro aspecto importante a destacar, diz respeito às áreas com ocorrência de solos expostos, que corresponde a 14\% da superfície da bacia, as quais foram consideradas como áreas de cultivo de cana, pois constituem porções do terreno destinadas ao desenvolvimento dessa cultura agrícola, porém aguardando novo plantio.

As áreas naturais são representadas pela vegetação de manguezal, que corresponde a $24 \%$ da área da microbacia, além de $6 \%$ da superfície correspondente às reservas de floresta Atlântica e $17 \%$ às matas ciliares.

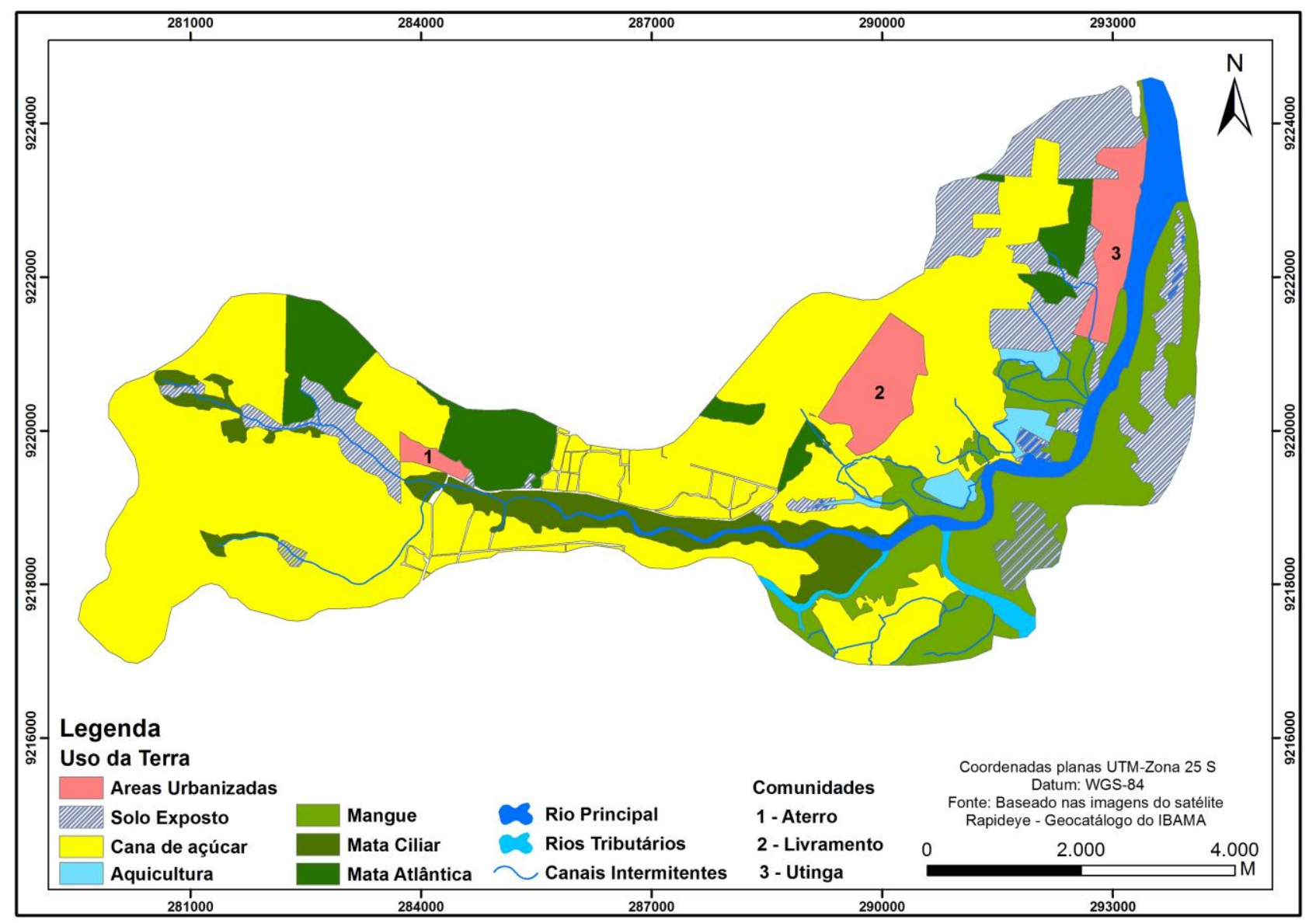

Figura 2: Uso das terras na bacia do rio Ribeira.

Em alguns locais, observa-se uma forte proximidade entre as áreas com vegetação natural e as plantações de cana-de-açúcar. A prática da queima do canavial, como forma cultural de manejo, que facilita a colheita, além de provocar destruição progressiva dos solos, potencializa o risco de destruição das áreas com vegetação natural.

A mata ciliar encontra-se presente, exclusivamente, em um pequeno trecho próximo ao povoado do Aterro, em sua margem esquerda, à jusante. A sua margem direita encontra-se completamente ocupada por plantações de cana-de-açúcar, sendo perceptível, em alguns trechos, a presença de vegetação de Mangue. 
A porção correspondente à água abrange os tanques de aquicultura intensiva (carcinicultura), além dos corpos d'água costeiros, que compreende o espelho d'água correspondente às águas do rio Sanhauá. A carcinicultura representa apenas $2 \%$ do uso da terra na área.

\subsection{GEOMORFOLOGIA}

A partir da classificação proposta por Ross (1992), foi possível distinguir duas grandes unidades geomorfológicas na área em estudo: os Tabuleiros Costeiros e a Planície Fluvial (Figura $3)$.

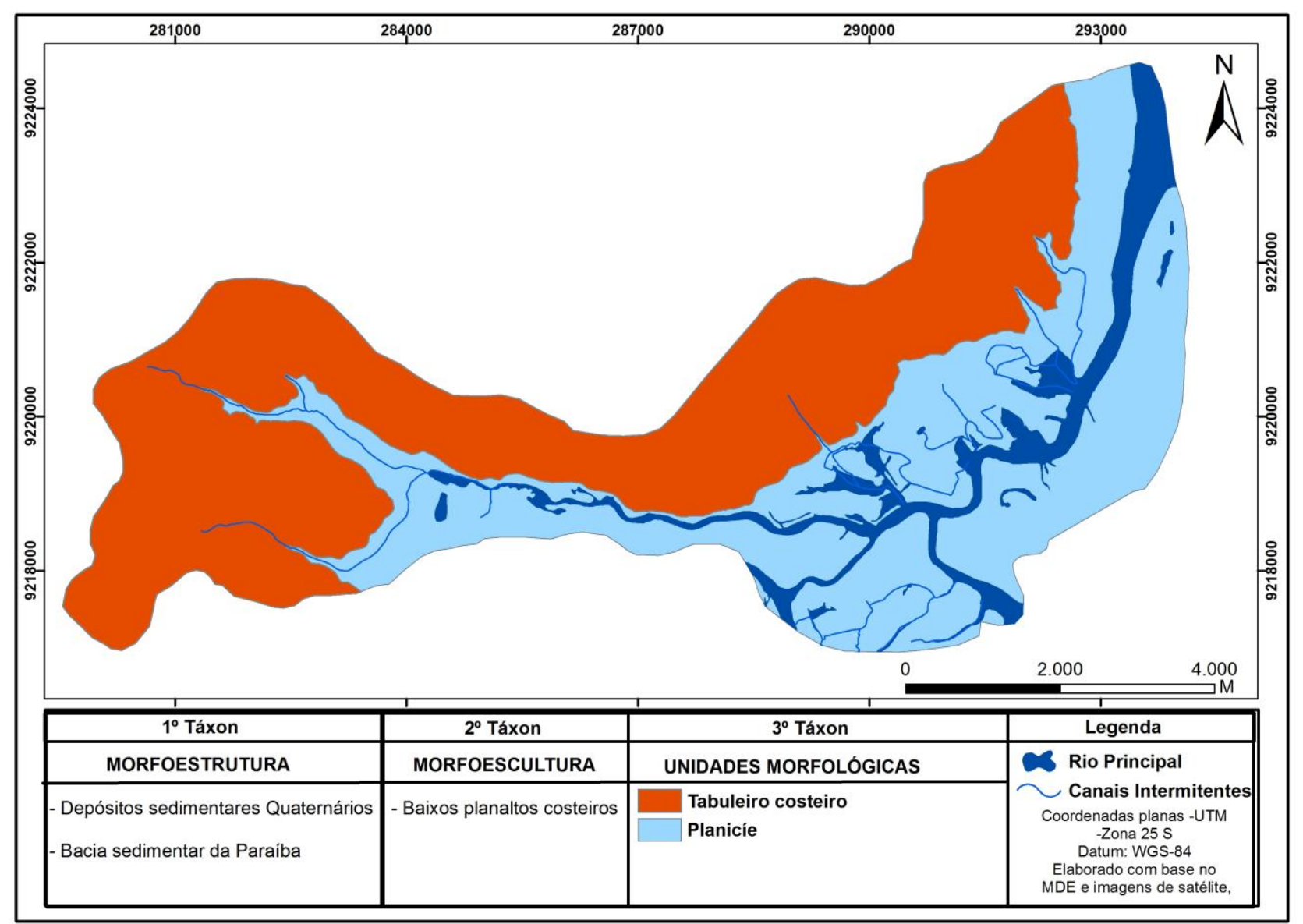

Figura 3: Mapa geomorfológico da bacia do rio Ribeira.

O mapa geomorfológico monstra o conjunto das unidades geomorfológicas que perfazem a área em estudo, constituindo um documento importante para a contextualização dos processos erosivos/deposicionais ocorrentes na área. Percebe-se, em geral, que sua maior parte é constituída por topos semiplanos e pela planície interdial, constituindo uma típica bacia de baixo curso. Nas porções balizadas por encostas, caracterizadas pelas rampas de colúvio, e nos terraços fluviais, é que se registram os maiores sinais de processos erosivos, os quais se iniciam na porção somital da 
vertente, chegando até o contato com a planície interdial, onde se registram processos agressivos de assoreamento.

Na margem esquerda da microbacia, as formas com topos convexos correspondem à porção dos tabuleiros costeiros cuja segmentação dos interflúvios produziu um relevo semiplano, de aspecto colinoso. Correspondem às áreas mais elevadas, com altitude máxima de 90 metros e suaves declives para leste, como resultado dos processos erosivos continentais, constituídos basicamente por sedimentos arenoargilosos mal consolidados da Formação Barreiras (Figura 4).

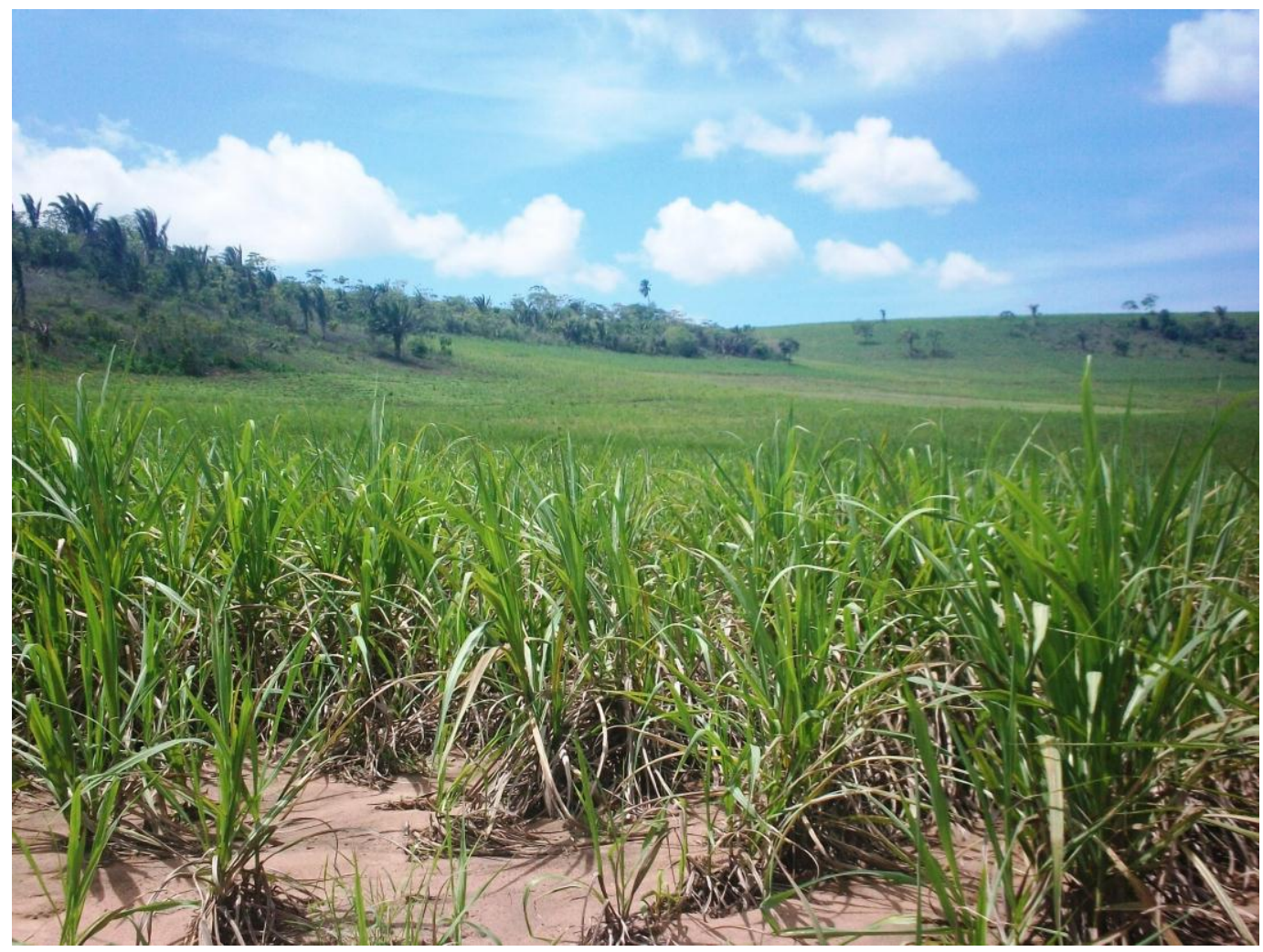

Figura 4: Rampas de colúvio na porção norte da área em estudo.

O seu topo apresenta baixo gradiente erosivo e predomínio dos processos da pedogênese, decorrente de sua suave inclinação, facilitando a infiltração da água de chuvas no solo. O material arenoso que compõe essa unidade do relevo funciona como uma esponja porosa, permitindo que a água da chuva infiltre, carreando os sedimentos finos e nutrientes para o subsolo.

\subsection{SUSCETIBILIDADE À EROSÃO}

Pode-se afirmar com clareza que, na microbacia do rio da Ribeira, o cultivo da cana-deaçúcar em determinadas parcelas do relevo é o fator que está diretamente associado ao grande montante de perda de solo. 
Sob domínio da ação humana, nas vertentes e terraços, ocorre a alteração da dinâmica natural dos processos geomorfológicos, pois essa situação acentua o processo de transporte do material erodido para a planície, contribuindo para o processo de assoreamento do rio da Ribeira.

Em geral, As vertentes apresentam suaves inclinações, entre 8 e 13\%, podendo chegar a $45 \%$ em alguns pontos, em direção ao leito do rio analisado. Este setor da microbacia se encontra mais susceptível aos processos erosivos, como resultado da associação do material sedimentar que a compõe e sua inclinação, o que lhe confere maior fragilidade frente aos processos erosivos (Figura $5)$.

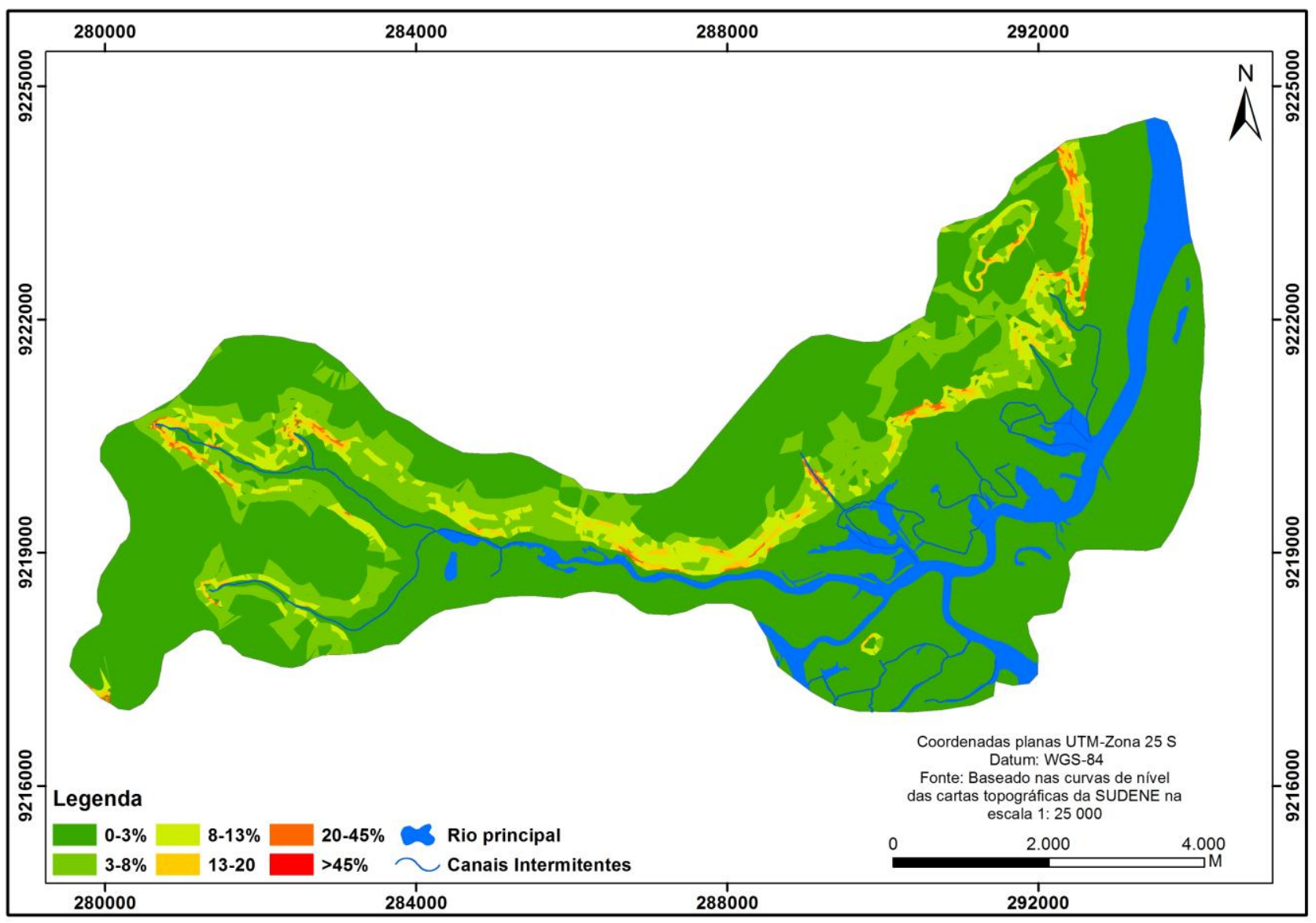

Figura 5: Mapa de declividade da área em estudo

Neste setor, também foi verificado o plantio da cana-de-açúcar, contribuindo para que os processos erosivos se acentuem ainda mais, pois o desenvolvimento dessa atividade não considera as características geomorfológicas e pedológicas da área, sem apresentar nenhum tipo de manejo adequado à conservação dos solos. Esse caso é bastante perceptível nas áreas cultivadas, localizadas entre os povoados do Aterro e do Distrito de Livramento, visto estarem inseridas exatamente sobre as vertentes. Nesta localidade, as vertentes se comportam, em geral, como rampas de suave inclinação, estabilizadas pelo próprio colúvio que se depositou em sua base por meio dos processos 
naturais de deposição. No entanto, o intenso desmatamento provocado para fins agrícolas tem se constituído como um fator que potencializa os processos erosivos, tornando-os mais intensos e, portanto, impactantes ao meio.

É perceptível, em toda a extensão da microbacia, a ação erosiva sobre as vertentes e o transporte de grande quantidade de sedimentos arenosos, além da exposição do solo decorrente desse processo. Na porção somital da vertente, foram identificados a formação de pequenas cabeceiras de drenagem e a canalização dos fluxos, chegando a formar intensos ravinamentos (Figura 6).

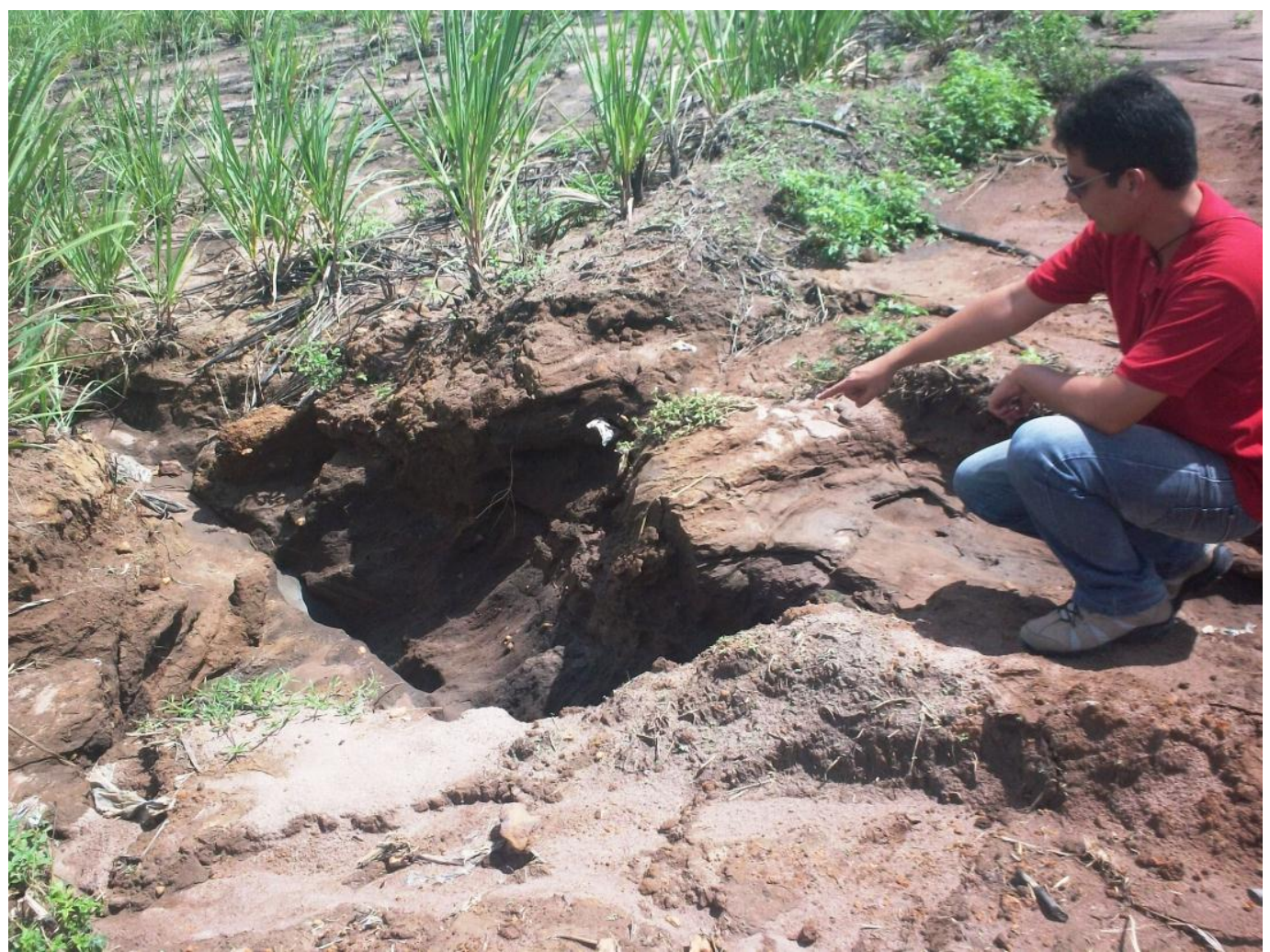

Figura 6: Formação de cicatrizes erosivas na porção somital da vertente em virtude da canalização de fluxos superficiais, resultando em intenso processo erosivo.

Essa situação é potencializada pela falta da vegetação original que outrora compunha essa unidade geomorfológica, onde, atualmente, o solo se encontra exposto, aguardando preparação para o plantio da cana-de-açúcar, tornando-o vulnerável ao impacto direto da gota da água da chuva, desencadeando o início do processo erosivo e a ampliação dessas feições ao longo do tempo.

Nas áreas urbanas, mais precisamente no Distrito de Livramento, a concentração de esgotos numa galeria pluvial, resultou na formação de uma voçoroca, dando origem ao mais acentuado processo erosivo da área analisada. Essa feição erosiva apresenta dimensões aproximadas de 10 
metros de largura por 30 metros de profundidade, estendendo-se por mais de 200 metros de comprimento.

É perceptível a presença de vegetação se desenvolvendo na parte mais profunda da feição, o que demonstra certo nível de estabilização, bem como a presença de troncos de árvores caídas provenientes das áreas superiores já erodidas (Figura 7).

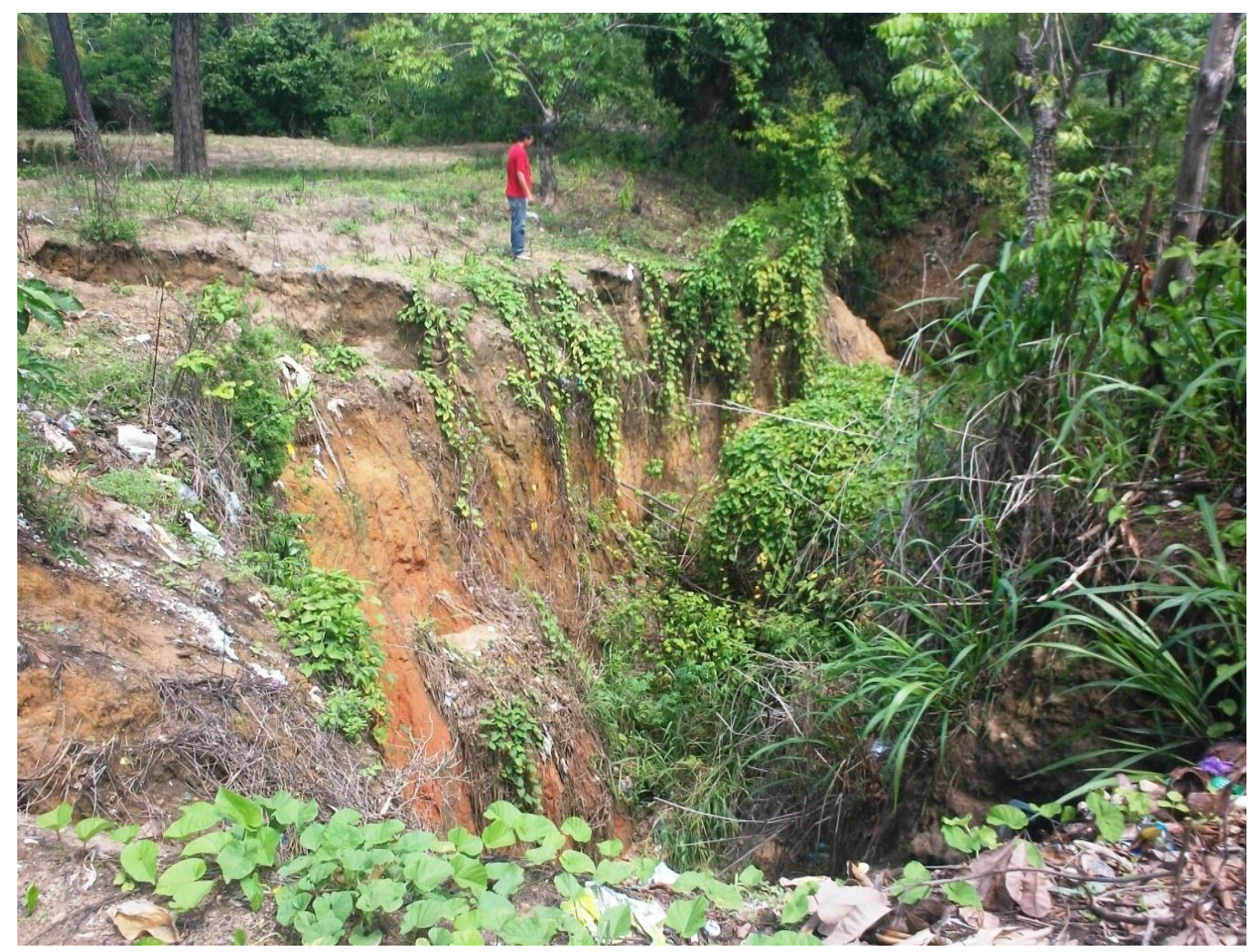

Figura 7: Voçoroca formada na área urbana do Distrito de Livramento.

Com base nas informações obtidas através do mapa de suscetibilidade erosiva, fica evidente que é sobre as vertentes que ocorrem os processos erosivos mais acentuados, visto ser uma área onde o uso da terra vem interferindo enfaticamente na dinâmica geomorfológica da região (Figura 8).

Verifica-se, portanto, que áreas com alta suscetibilidade à ocorrência de erosão perfazem uma área de $23.522 \mathrm{~m}^{2}$, enquanto as áreas de baixa suscetibilidade a $10.538 \mathrm{~m}^{2}$, demonstrando uma elevada propensão da microbacia frente à ocorrência desse tipo de processo.

Em consequência disto, as alterações realizadas no topo, vertentes e terraços irão se refletir diretamente na planície interdial, pois a grande carga de sedimentos depositados resultará no assoreamento do rio da Ribeira, alterando sua dinâmica natural, formando diversos leques aluviais, que se projetam para a calha fluvial, colmatando-a. Ademais, pode-se citar uma possível 
contaminação do solo e das águas do rio, pelo uso indiscriminado de agrotóxicos nas plantações de cana-de-açúcar.

Além disso, a localização de tanques de criação de camarão na planície interdial também se apresenta como um fator que contribui para os impactos que ocorrem nesse ambiente, pois, esta atividade se utiliza das condições favoráveis, como a salinidade da água do estuário para instalarem seus tanques criação, causando o assoreamento da calha fluvial e a contaminação das águas.

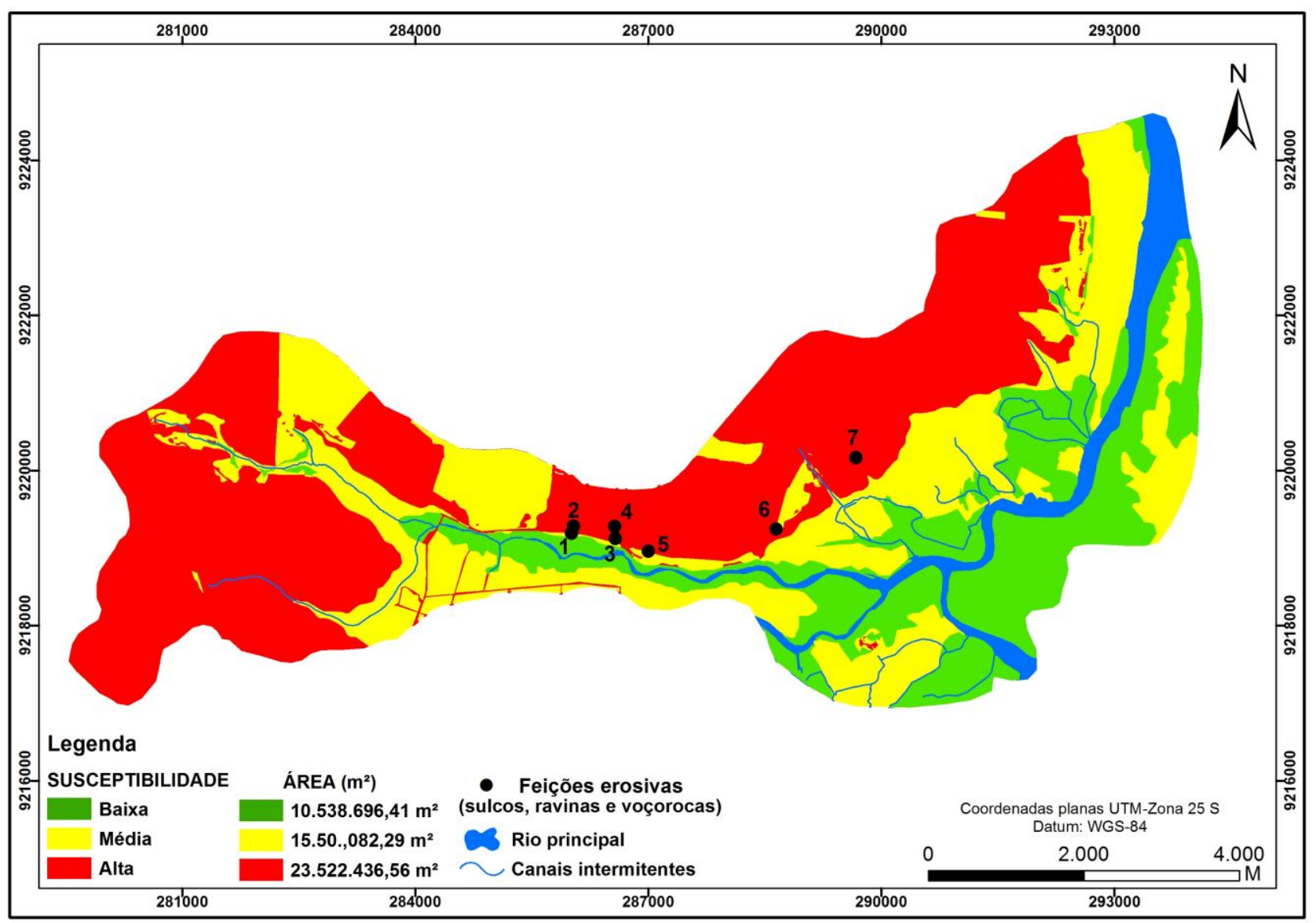

Figura 8: Mapa de Suscetibilidade Erosiva.

\section{CONSIDERAÇÕES FINAIS}

Os dados obtidos na presente pesquisa mostram que a associação da atividade canavieira com as unidades geomorfológicas presentes na área tem provocado sérios danos à dinâmica natural da bacia, a partir da intensificação dos processos de erosão e deposição. Isso porque o plantio da cana-de-açúcar é realizado sem considerar as características naturais do meio, principalmente, em relação ao solo e ao relevo.

O cruzamento entre as informações referentes ao uso da terra, a declividade e as unidades geomorfológicas da microbacia do rio da Ribeira permite afirmar que é nas vertentes onde ocorrem 
os processos erosivos mais acentuados, gerando uma quantidade significativa de sedimentos transportados para as baixadas.

O aumento da quantidade de sedimentos lançados no leito do rio da Ribeira pode estar ocasionando, também, a contaminação do solo e dos corpos hídricos por agrotóxicos utilizados nas plantações, gerando forte desequilíbrio no sistema natural da microbacia analisada.

Além disso, nas áreas urbanas, a destinação incorreta de efluentes tem sido responsável pela formação de grandes incisões lineares, a exemplo da voçoroca existente no Distrito de Livramento.

Portanto, entende-se que a intensificação dos processos erosivos e deposicionais na microbacia do rio da Ribeira, está associada ao modo como ocorre o uso da terra e ao tipo de manejo agrícola, que podem ser classificados como insustentáveis, diante da gravidade das características dos processos naturais que marcam as unidades geomorfológicas que compõem a microbacia do rio da Ribeira.

\section{REFERÊNCIAS}

ARAÚJO, G. H. S.; ALMEIDA, J. R.; GUERRA, A. J. T. Gestão ambiental de áreas degradadas. Rio de Janeiro: Bertrand Brasil, 2007.

BARBOSA, J. A. A deposição carbonática na faixa costeira Recife-Natal: aspectos estratigráficos, geoquímicos e paleontológicos. 270f. Tese (Doutorado). Programa de PósGraduação em Geociências. Universidade Federal de Pernambuco, 2007.

BESKOW, S., MELlO, C.R., NORTON, L.D., CURI, N., VIOLA, M.R., AVANZI, J.C. Soil prediction in the Grande River Basin, Brazil using distributed modelling. Catena 79 (1), 49-59, 2009.

BRASIL. Ministério da Agricultura, Pecuária e Abstecimento. Empresa Brasileira de Pesquisa Agropecuária/Unidade de Execução e Pesquisa em Recife, 2006. Solos do Nordeste. Recuperado de www.uep.cnps.embrapa.br/solos/index.html.

BRASIL. Ministério do Planejamento, Orçamento e Gestão. Instituto Brasileiro de Geografia e Estatística (IBGE). Manual Técnico de Uso da Terra, Brasília, DF, 2006.

CARVALHO, M. Estado da Paraíba: classificação geomorfológica. João Pessoa: UFPB, 1982.

FUJIHARA, A.K. Predição de erosão e capacidade de uso do solo numa microbacia do oeste paulista com suporte de geoprocessamento. 118p. Dissertação (Mestrado), Universidade de São Paulo, 2002.

GOUDIE, A. The human impact on the natural environment. Oxford, Blackwell Publishers, 1990. 
GUERRA, A. J. T. O Início do Processo Erosivo. In: GUERRA, A. J. T.; SILVA, A. S.; BOTELHO, R. G. M. (Eds.). Erosão e Conservação dos Solos: conceitos, temas e aplicações. $6^{a}$ Ed. Rio de Janeiro: Bertrand Brasil, 2010.

GUERRA, A. J. T.; MARÇAL, M. S. Geomorfologia Ambiental. Rio de Janeiro: Bertrand Brasil, 2012.

LEPSCH, I. F. Formação e conservação dos solos. São Paulo: Oficina de Textos, 2010.

MELO, A.; HECKENDORFF, W.; ALVES, E.; GUIMARÃES, M. O meio ambiente natural: componentes abióticos e bióticos. In: Melo, A. (Eds.). Projeto de Pesquisa: Vale do Jaguaribe. João Pessoa: UNIPÊ, 2001.

MOREIRA, M.; TARGINO, I. Capítulos de Geografia Agrária da Paraíba. João Pessoa: EDUFPB, 1997.

MONTGOMERY, D. R. Soil erosion and agricultural sustainability. PNAS 104:13268-13272, 2007.

PEREIRA, M.; ALVES, R. Composição florística de um remanescente de Mata Atlântica na Área de Proteção Ambiental Barra do Rio Mamanguape, Paraíba, Brasil. Revista de Biologia e Ciências da Terra, v.1, n.7, p.1-10, 2007.

PEREIRA, M.; MONTEIRO, D.; SILVA, N.; MOURA, M. Avaliação quantitativa das precipitações diárias intensas na cidade de João Pessoa, Paraíba. Revista Geonorte, v.1, n.5, p.921-929, 2012.

ROSS, J. L. S. O registro dos fatos geomórficos e a questão da taxonomia do relevo. Revista do departamento de Geografia da FFLCH/USP, n.8, p.63-74, 1992.

Recebido em: 02/04/2018

Aceito para publicação em: 10/06/2018 